non-attendance rate was 31\%. The condition with most frequent non-attendance was genital warts, at $38 \%$. In response to this, a specific walk-in warts review (WWR) clinic was introduced and its impact reviewed.

Methods A retrospective review of non-specialist doctor and nurse follow-up appointments for 2 weeks (19/5/14-1/6/14), 6 months following the establishment of the WWR clinic, compared to 2 weeks prior to its introduction $(25 / 2 / 13-10 / 3 / 13)$.

Results In total 85 patients were given a booked non-specialist follow-up appointment in the 2014 sample, compared to 103 in the 2013 sample. 19 patients attended for warts review (15 in the WWR clinic, 4 booked appointments) in the 2014 sample, compared to 12 patients who attended their booked warts review in the 2013 sample. Overall the non-attendance rate for non-specialist booked reviews was $28 \%$ in the 2014 sample, compared to $31 \%$ in the 2013 sample ( $\mathrm{p}=0.68)$. Non-attendance in the 2014 sample was most frequent for gonorrhoea test of cure, blood tests and vaccines $(21 \%, 13 \%$ and $13 \%$ of nonattendees, respectively).

Discussion Overall the non-attendance rate for follow-up appointments was not significantly lower following introduction of the WWR clinic. However convenience for patients has improved. Further work is needed to ascertain the optimal way of delivering best practice clinical care whilst ensuring efficient service provision.

\section{P165 DIFFERING TRAJECTORIES OF SEXUAL HEALTH CLINIC (SHC) ATTENDANCE IN MEN-WHO-HAVE-SEX-WITH-MEN (MSM) AND HETEROSEXUAL MEN: CAN WE USE THESE TO PLAN SERVICES?}

${ }^{1}$ Miriam Samuel, ${ }^{2}$ Martina Furegato*, ${ }^{2}$ Gwenda Hughes, ${ }^{3,4}$ Jackie Cassell, ${ }^{2}$ Hamish Mohammed. 'Guy's and St Thomas' NHS Foundation Trust, London, UK; ${ }^{2}$ Public Health England, London, UK; ${ }^{3}$ Brighton and Sussex Medical School, Brighton, UK; ${ }^{4}$ Kent Surrey and Sussex Public Health England Centre, West Sussex, UK

\subsection{6/sextrans-2015-052126.208}

Background Understanding why patients attend SHCs can inform service development.

Aims To describe SHC attendance patterns amongst heterosexual men and MSM.

Methods Heterosexual and MSM first attending SHC in 2012 were identified through the GUM Clinic Activity Dataset-v2 and followed for 365 days. Attendance frequency and outcomes were recorded. Attendance outcomes were classified: 'test-only' for negative sexually transmitted infection (STI) testing (chlamydia, gonorrhoea, syphilis, HIV) and no other service/diagnosis; 'any-STI'; 'non-STI' for other conditions; 'other-GU-service' such as health advice, post-exposure prophylaxis/vaccination; and 'Other' episodes not requiring treatment.

Results 809,106 attendances were identified among 438,609 men (81.37\% heterosexual, $12.96 \%$ MSM). The Table describes age, visit frequency and attendance outcomes. Multivariate Poisson regression adjusted for age, ethnicity, and area-level deprivation demonstrated that attendance frequency was greater amongst MSM (Incidence Rate Ratio 1.69, p < 0.001) and men with any-STI at first attendance (IRR 1.67, p < 0.001).

Discussion Men who are appropriate for clinically and cost-efficient pathways, such as telephone review and home testing, could be identified at first attendance and offered customised care pathways stratified by risk.

\begin{tabular}{lll} 
Abstract P165 Table 1 & Men attending sexual health clinics \\
\hline & \multicolumn{1}{l}{ Heterosexual } & MSM \\
& $\%$ & $\%$ \\
\hline Age at first attendance & & \\
$\quad \leq 15$ & 0.48 & 0.18 \\
$16-19$ & 10.01 & 5.13 \\
$20-24$ & 26.37 & 18.06 \\
$25-34$ & 35.87 & 35.01 \\
$35-44$ & 15.37 & 22.14 \\
$45-64$ & 10.80 & 17.73 \\
$\geq 65$ & 1.09 & 1.75 \\
No. of attendance in 365 days & & \\
1 & 65.66 & 39.71 \\
2 & 19.88 & 19.89 \\
3 & 7.03 & 13.25 \\
4 & 3.20 & 8.97 \\
$\geq 5$ & 4.22 & 18.18 \\
Visit frequency, median (IQR) & $1(1-2)$ & $2(1-4)$ \\
Attendance outcomes & & 21.29 \\
Test-only & 41.44 & 13.88 \\
Any-STI & 22.17 & 1.77 \\
Non-STI & 3.41 & 19.99 \\
Other-GU-service & 6.70 & 49.23 \\
Other & 31.93 &
\end{tabular}

\section{P166 "IF YOU BUILD IT, THEY WILL COME": HOW THE TARGETED LOCATION OF A SEXUAL HEALTH CLINIC WITHIN THE SOCIAL HEART OF AN AT RISK COMMUNITY CAN SIGNIFICANTLY INCREASE THE DETECTION AND MANAGEMENT OF INFECTIONS}

Elizabeth Kershaw*. Chelsea and Westminster Hospital NHS Foundation Trust, 56 Dean Street, London, UK

\subsection{6/sextrans-2015-052126.209}

Background/introduction A 2009 decision to relocate a sexual health and HIV clinic to an area with the highest density of gay venues in Europe was based on the belief that positioning a service directly where a high risk and vulnerable population socialised would facilitate regular sexual health screening for men who have sex with men (MSM), improve the early detection of HIV and other infections, and reduce onward transmission.

Aim(s)/objectives This study examined whether the relocation had led to the anticipated increase in overall attendances and pathology specifically in MSM beyond the increase in national STI rates reported by Public Health England. As the relocation effect cannot be directly measured, any significant discrepancy between the two rates could be used as a proxy for success.

Methods Attendances and infection rates for 2008 at the former clinic were compared with those for 2013 at the new clinic (from KC60 codes). The overall infection increase was then compared with the increase in STI rates reported nationally by Public Health England between 2008 and 2013. The specific proportion of infections in MSM was compared with the national data for 2013.

Results Attendances increased by 22\% from 56,181 to 68,395, with $61 \%$ of patients in 2013 reported as homosexual. The increase in infections significantly exceeded both this and rates reported by PHE, with $84 \%$ of infections reported in MSM. 
Abstract P166 Table 1 If you build it, they will come

\begin{tabular}{|c|c|c|c|c|c|c|}
\hline & Number of diagnoses & Number of diagnoses & Clinic increase & PHE increase & 2013 Clinic & 2013 PHE \\
\hline Infection & 2008 & 2013 & $2008-13$ & 2008-13 & STI in MSM & STI in MSM \\
\hline Syphilis & 116 & 516 & $345 \%$ & $13 \%$ & $94 \%$ & $81 \%$ \\
\hline Gonorrhoea & 208 & 3055 & $1369 \%$ & $95 \%$ & $95 \%$ & $63 \%$ \\
\hline Chlamydia & 539 & 2346 & $335 \%$ & -8\% (in GUM settings) & $66 \%$ & $17 \%$ \\
\hline HIV & 175 & 381 & $118 \%$ & $-17 \%$ & $87 \%$ & $49 \%$ \\
\hline
\end{tabular}

Discussion/conclusion There was a significant disproportionate rise in the detection of infection compared to attendances. This suggests the intervention was successful at reaching the high risk groups targeted.

\section{P167 WEEKLY CASE REVIEW AND TELEPHONE FOLLOW UP TO IMPROVE MANAGEMENT OF PELVIC INFLAMMATORY DISEASE (PID) IN A SEXUAL HEALTH CLINIC}

Brenton Wait, Kate Forey*, Katherine Coyne. Homerton University Hospital NHS Foundation Trust, London, UK

\subsection{6/sextrans-2015-052126.210}

Introduction Previous audits of our management of Pelvic Inflammatory Disease (PID) have shown poor compliance with guidelines, including missing pregnancy testing (PT) in 47\% and no follow up in $66 \%$.

Aims To improve management and follow up of PID.

Methods We introduced a weekly notes review of all PID cases attending our sexual health service. Clinicians received feedback about incorrect antibiotics, or failing to do pregnancy testing (PT). An unsolicited phone call was made to patients not attending 2 week review, to discuss symptoms, treatment completion, partner treatment and abstinence. This is a review 4 months September-December 2014.

Results 101 patients were treated for PID. 25\% did not have a PT documented,. Overall 46\% received recommended antibiotics (30\% in the first 2 months, $64 \%$ in the last 2 months). $29 \%$ attended for review. Phone calls reached $28 \%$ of the remaining patients. $90 \%$ of patients contacted or attending had completed treatment. 53\% still had symptoms

Discussion Weekly review allowed for regular feedback to clinicians about documentation and management. Pregnancy testing rates were improved on previous results, though still of concern. Antibiotic prescribing was initially poor, probably due to a recent change in protocol. This improved over the course of the 4 months, suggesting the value of weekly targeted feedback. Unfortunately, phone calls were often unsuccessful, though patients were happy to receive calls. A significant number of patients still had symptoms, undermining our previous assumption of cure where patients failed to attend follow up. To improve telephone follow up, pre-arranged times or methods of contact may be worth trialling.

\section{P168 INTRODUCING CHANGE, IMPROVING PRODUCTIVITY IN TIMES OF AUSTERITY...CAN IT BE DONE?}

Lina Hijazi*, Charlotte Hopkins, Monica Lascar. Barts Health NHS Trust, London, UK

10.1136/sextrans-2015-052126.211

Background/introduction A number of service changes (expanded opening hours, increased access to contraception) were implemented within existing resource and were successful at reversing GUM declining attendances trend. We describe and evaluate a "grass roots" process used in our clinic to do this.

Aim(s)/objectives The aims were to evaluate:

- Impact of the process on staff motivation and team dynamics

- Staff perspective on the change process

Methods Clinical leads outlined change triggers and engaged team in vision development during a series of away mornings. Subsequently, staff members took lead on designing, planning and implementation of work streams. All staff were invited to complete a survey monkey questionnaire exploring personal experience of change, impact of change on team dynamics and job satisfaction 3 months afterwards.

Results $17 / 19$ potential respondents completed the questionnaire either fully or partially. 9-11/17 (53-65\%) felt they were very supported in the process. 11-14/17 (65-82\%) felt the team work was collaborative and problem solving. $7 / 14$ had no change in their job satisfaction, rated as good. 2/14 rated their job satisfaction as very poor before the process, but no one (0/14) did so afterwards. No staff rated their job satisfaction as excellent before the changes and 1/14 did so afterwards. Factors cited by staff to positively influence the process were feeling valued, a clear vision, using the SMART goal model to problem solve. 9/17(53\%) would recommend this process to other departments.

Discussion/conclusion We have delivered effective change whilst empowering individuals and teams and improving patient care, all within resource.

\section{P169 EVALUATION OF A PATIENT INFORMATION LEAFLET DESIGNED TO AID THE PATIENT EXPERIENCE OF A NEWLY INTEGRATED SEXUAL HEALTH SERVICE}

Sarah Jones, Cara Saxon*. Bridgewater Community Health Care NHS Foundation Trust, Manchester, UK

\subsection{6/sextrans-2015-052126.212}

Background/introduction Four services merged to create one new integrated sexual health $(\mathrm{SH})$ service following a tender process. A new hub opened and six spoke clinics remained in existing locations. To address concerns about the implementation of integration a patient information leaflet (PIL) was designed explaining the new service (including how clinics might be different for returning patients, all services offered, and explanation of STI/HIV testing).

Aim(s)/objectives To evaluate the PIL.

Methods The new PILs were handed to all patients across the service (excluding two young persons services) at reception to read before seeing the clinician. During the first two weeks of role out patients were asked to complete a paper feedback form about the PIL. 